\title{
ALEXANDRE GEFEN, Réparer le monde. La littérature française face au XXI ${ }^{\mathrm{e}}$ siècle
}

\section{Francesca Lorandini}

\section{OpenEdition \\ Journals}

\section{Edizione digitale}

URL: https://journals.openedition.org/studifrancesi/23152

DOI: 10.4000/studifrancesi.23152

ISSN: 2421-5856

\section{Editore}

Rosenberg \& Sellier

\section{Edizione cartacea}

Data di pubblicazione: 1 avril 2020

Paginazione: 217

ISSN: 0039-2944

\section{Notizia bibliografica digitale}

Francesca Lorandini, «ALEXANDRE GEFEN, Réparer le monde. La littérature française face au xxl ${ }^{\circledR}$ siècle», Studi Francesi [Online], 190 (LXIV | I) | 2020, online dal 01 mai 2020, consultato il 03 août 2021. URL: http://journals.openedition.org/studifrancesi/23152 ; DOI: https://doi.org/10.4000/studifrancesi. 23152

Questo documento è stato generato automaticamente il 3 août 2021.

\section{(†) $९$

Studi Francesi è distribuita con Licenza Creative Commons Attribuzione - Non commerciale - Non opere derivate 4.0 Internazionale. 


\title{
ALEXANDRE GEFEN, Réparer le monde. La littérature française face au XXI siècle
}

\author{
Francesca Lorandini
}

\section{NOTIZIA}

ALEXANDRE GEFEN, Réparer le monde. La littérature française face au XXI ${ }^{\mathrm{e}}$ siècle, Paris, Corti, 2017, $392 \mathrm{pp}$.

1 Secondo A. Gefen all'interno della letteratura francese contemporanea si sarebbe fatta strada una concezione terapeutica della scrittura che avrebbe determinato una trasformazione delle pratiche, dei generi, delle norme e, più in generale, del discorso letterario. Il nuovo paradigme clinique sarebbe evidente anzitutto nell'uso che della letteratura viene fatto: in mancanza di una religione o di un progetto politico adeguato essa avrebbe infatti oggi la funzione di «réparer nos conditions de victimes, corriger ces traumatismes de la mémoire individuelle ou du tissu social» (p. 11). Il termine letteratura va inteso in senso ampio perché un orizzonte comune legherebbe i manuali di self-help, le guide ai processi di empowerment, la creazione di atelier di scrittura a fine terapeutico, i memoriali o i racconti testimoniali ai libri di Pierre Michon, Emmanuel Carrère, Philippe Forest, Annie Ernaux, Pascal Quignard, Patrick Modiano, Chloé Delaume o Camille Laurens (per citare alcuni dei nomi che tornano più spesso nel saggio). Dopo il ritorno del soggetto, della Storia e del racconto di fine Novecento, la letteratura francese contemporanea andrebbe ora vista come un «dispositif social ou symbolique opérant sur les consciences et sur les cœurs» (p. 17). Una letteratura empatica, che aiuta, che mira a prendersi cura della vite dimenticate, delle comunità schiacciate dalla Storia o dal progresso, dei deboli, e in cui si articola continuamente quella difficile impresa di essere se stessi che è l'imperativo narcisistico del nostro tempo. Per descrivere questo dispositivo Gefen struttura l'analisi in sette sezioni, che 
corrispondono ai sette modi in cui la letteratura oggi "fa fronte" alla realtà: «Face à soi» (cosa ne è della particolarità di ogni uomo all'epoca del Be yourself di massa? l'idea di un'unicità della persona ha ancora senso?), «Face à la vie» (l'autobiografia come modalità di investigazione della realtà, ma anche come forma di riconoscimento e legittimazione dove le reti di inserimento e integrazione sociale risultano manchevoli), «Face aux traumas» (in che modo si declina il trio trauma, resilienza e compassione; la lettura come strumento di formazione esistenziale), «Face à la maladie» (come si è sviluppata una letteratura di accompagnamento della malattia e dell'elaborazione del lutto, seguendo diverse traiettorie che da Hervé Guibert arrivano fino a Maylis de Kerangal), «Face aux autres» (cura di sé e empatia per gli altri: in che modo l'etica del care pervade la letteratura contemporanea), «Face au monde» (come in letteratura si articola il rapporto tra essere umano, territorio e comunità), "Face au temps» (l'ossessione memoriale, il tentativo di guarire le ferite della Storia). A chi, con Bataille, è abituato a pensare la letteratura in relazione al male, l'impostazione di questo saggio potrebbe sembrare quanto meno moraleggiante. È questo certo il rischio maggiore di un libro che ha però il grande pregio di proporre una visione d'insieme che non si limita al regesto dei libri pubblicati negli ultimi vent'anni, ma ne dà un'interpretazione coerente, e persuasiva. 